\title{
Bi-thalamic infarction due to a suprasellar germinoma
}

\author{
Julien Francisco Zaldivar-Jolissaint • Marc Kotowski • \\ Philippe Maeder • Marc Levivier • Roy Thomas Daniel
}

Received: 19 January 2015 / Accepted: 4 March 2015 / Published online: 19 March 2015

(C) Springer-Verlag Wien 2015

\section{Dear Editor,}

Through this short report, we would like to share with the Acta Neurochirurgica readership the interesting case of a young man who presented to our clinic after the acute development of dysarthria. Investigations led to the diagnosis of a right thalamic stroke from an unusual cause: a third ventricle germinoma. Months later the patient was re-hospitalized in a comatose state due to an acute contralateral thalamic stroke resulting in the classic bi-thalamic paramedian stroke syndrome. Our case illustrates the variability of blood supply to the median and anterior thalamic territories and is to our knowledge the first report documenting both sequential paramedian bi-thalamic infarction and intracranial germinoma as a potential cause of thalamic ischemia.

Thalamic infarction is a well-described entity, but its clinical recognition remains difficult. The wide range of possible presenting symptoms and signs of thalamic infarction emerges from the diverse functional roles of the thalamic nuclei and the density of their spatial disposition. Four thalamic arterial territories and syndromes have been proposed, but a high degree of clinical overlap exists. As an example, the anterior territory can be vascularized by the paramedian artery in one-third of the population [1], and the Percheron artery can perfuse the paramedian territory bilaterally [7] (Fig. 1a-c).

We document here a unique case of sequential thalamic infarction emerging from a previously undescribed etiology.

J. F. Zaldivar-Jolissaint $(\bowtie) \cdot$ M. Kotowski $\cdot$ M. Levivier •

R. T. Daniel

Service de Neurochirurgie, Centre Hospitalier Universitaire Vaudois (CHUV) and University of Lausanne (Unil), Lausanne, Switzerland e-mail: julienzaldivar@gmail.com

P. Maeder

Service de Radiologie, Centre Hospitalier Universitaire Vaudois (CHUV) and University of Lausanne (Unil), Lausanne, Switzerland
A 22-year-old male without previous medical history presented to our clinic after the acute development of dysarthria. Neurological examination also revealed mild left-sided hemiparesis and cognitive impairment. Brain MRI showed a heterogeneously enhancing mass of the third ventricle. It was located posteriorly to the pituitary stalk and optic chiasma and extended posteriorly to the aqueduct of Sylvius (Fig. 1d-e). Radiological differential diagnosis encompassed germinoma [6], hypothalamic glioma [2], and embryonal and neuroblastic tumors [3, 5]. Most remarkably, a distal acute right thalamic infarction was present at the level of the anterior and dorsomedial nuclei as seen in diffusion-weighted imaging (Fig. 1g). Infarction was most probably due to either tumor mass effect or vascular infiltration of the right paramedian artery. The paramedian artery usually emerges from the posterior cerebral artery (P1 segment) and vascularizes the dorso-median and sometimes anterior thalamic nuclei (Fig. 1b) [7, 8]. Thalamic ischemia was thus the acute presenting event that underlined the initial clinical picture.

Surgery was undertaken via a subfrontal approach, through the lamina terminalis. Post-operative imaging at $48 \mathrm{~h}$, showed as expected, an incomplete tumor excision (Fig. 1f). Histopathological examination was conclusive for germinoma. After adjuvant radiotherapy, neuro-rehabilitation allowed excellent functional recovery. Seven months after the initial presentation, the patient was found comatose by his parents and brought urgently to the hospital. MRI revealed a new controlateral left dorso-median thalamic infarction. Cardiac and vascular sources of emboli (including possible patent foramen ovale) were excluded through the appropriate investigations. The second infarction was thus probably due to postradiotherapy vasculopathy or new vascular infiltration/ compression of the left paramedian artery (Fig. 1h).

Our report shows the clinical pattern of polar and paramedian thalamic territory infarction emerging from a right paramedian artery occlusion [8] (Fig. 1b). Subsequent contralateral paramedian infarction resulted in the classic clinical 
Fig. 1 a Classic thalamic arterial territories, infarction syndromes, and their relative frequencies. $\mathbf{b}$ Absent tubero-thalamic artery variant. c Percheron artery variant. d Initial brain axial T1Gd MRI showing an enhancing third ventricle mass. e Initial brain sagittal T1-Gd MRI showing the antero-posterior extension of the tumor. f Post-operative brain T1Gd MRI at $48 \mathrm{~h}$ showing incomplete tumor excision (arrowhead). g Initial DTI MRI showing acute right anterior and dorso-median thalamic infarction (arrowhead). h DTI-MRI

7 months later showing an acute left dorso-median thalamic infarction after the development acute development of a comatose state (arrowhead)

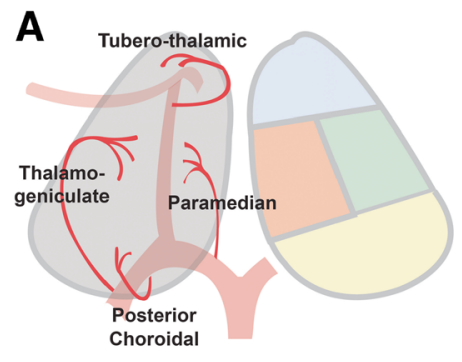

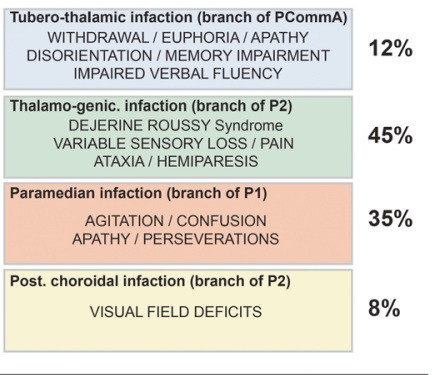

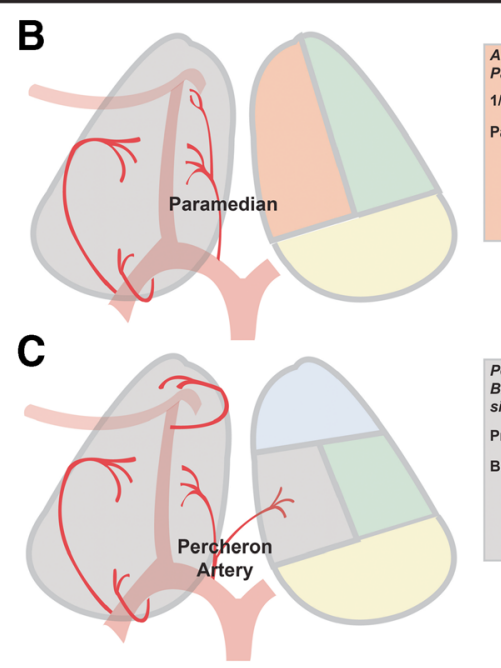

Absent tubero-thalamic artery anterior territor $1 / 3$ of the population Paramedian infarction

COGNITIVE AND MEMORY IMPAIRMENT APATHY / HEMIPARESIS / DYSARTHRIA
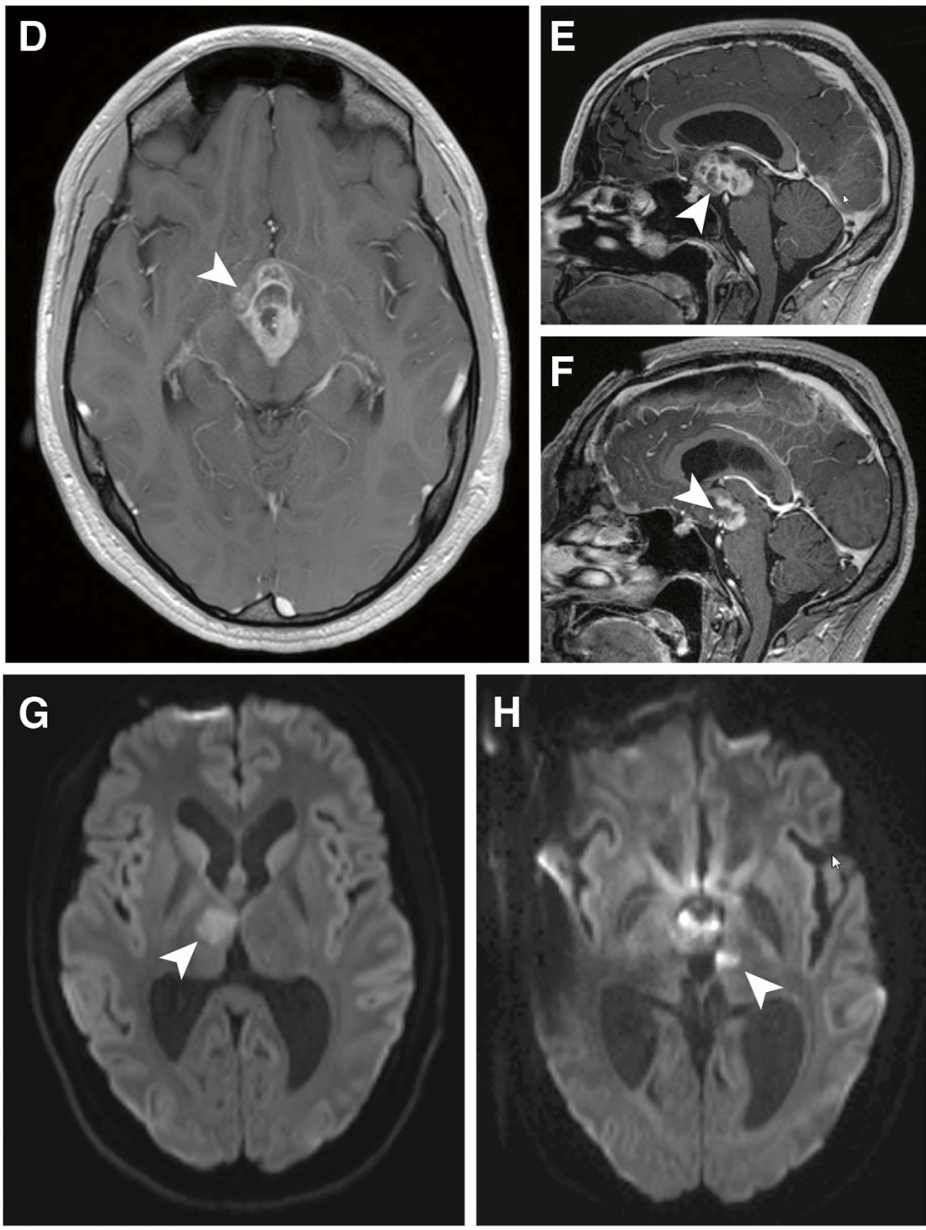
picture of bithalamic paramedian infarction, which usually emerges from a single ischemic event: a Percheron artery occlusion [4] (Fig. 1c).

Disclosures All authors certify that they have no affiliations with or involvement in any organization or entity with any financial interest (such as honoraria; educational grants; participation in speakers' bureaus; membership, employment, consultancies, stock ownership, or other equity interest; and expert testimony or patent-licensing arrangements), or nonfinancial interest (such as personal or professional relationships, affiliations, knowledge or beliefs) in the subject matter or materials discussed in this manuscript.

Patient consent The patient and his next of kin/guardian have consented to the journal submission of the case report.

Contributorship statement Julien Francisco Zaldivar-Jolissaint drafted the manuscript and built the figures.

Marc Kotowski co-drafted the manuscript and revised the figures.

Philippe Maeder revised the radiological aspects of the report.

Marc Leviver revised the text.

Daniel Roy provided final manuscript revision.

\section{Conflict of interest None.}

\section{References}

1. Bogousslavsky J, Regli F, Assal G (1986) The syndrome of unilateral tuberothalamic artery territory infarction. Stroke J Cereb Circ 17(3): 434-441

2. Bommakanti K, Panigrahi M, Yarlagadda R, Sundaram C, Uppin MS, Purohit AK (2010) Optic chiasmatic-hypothalamic gliomas: is tissue diagnosis essential? Neurol India 58(6):833-840

3. Deopujari CE, Kumar A, Karmarkar VS, Biyani NK, Mhatre M, Shah NJ (2011) Pediatric suprasellar lesions. J Pediatr Neurosci 6(Suppl1): S46-S55

4. Guberman A, Stuss D (1983) The syndrome of bilateral paramedian thalamic infarction. Neurology 33(5):540-540

5. Kollias SS, Barkovich AJ, Edwards MS (1991) Magnetic resonance analysis of suprasellar tumors of childhood. Pediatr Neurosurg 17(6): 284-303

6. Liang L, Korogi Y, Sugahara T, Ikushima I, Shigematsu Y, Okuda T, Takahashi M, Kochi M, Ushio Y (2002) MRI of intracranial germ-cell tumours. Neuroradiology 44(5):382-388

7. Percheron G (1973) The anatomy of the arterial supply of the human thalamus and its use for the interpretation of the thalamic vascular pathology. Z Für Neurol 205(1):1-13

8. Perren F, Clarke S, Bogousslavsky J (2005) The syndrome of combined polar and paramedian thalamic infarction. Arch Neurol 62(8): $1212-1216$ 